\title{
THE INFLUENCE OF SUNLIGHT ON TUBERCULOUS SPUTUM IN DENVER: A STUDY AS TO THE CAUSE OF THE GREAT DEGREE OF IMMUNITY AGAINST TUBERCULOSIS ENJOYED BY THOSE LIVING IN HIGH ALTITUDES.
}

\author{
By Williay C: Mrtchell, M.D., Denver, Eacteriologist, Denver Health \\ Department and St. Luke's Hospital, Associate Professor of Bacteri- \\ ology, University of Denver; and H. C. Chouch, A.M., M.I)., Denver, \\ late Jiacteriologist, Denver Health Department, and I'rofessor of \\ Bateriology and Hygiene, Unizersity of Colorado.
}

A CAREFU and painstaking review of the literature in English, French, German, and Italian, since the discovery of the tubercle bacillus, has revealed that there are reported but three series of experiments with reference to the effect of direct sunlight on the viability and virulence of the tubercle bacillus. There stands recorded, however, a long list of experiments made to determine the effect of other natural agents in destroying the virulence of this bacillus, such as putrefuctive changes, the influence of soil, desiccation, and, lastly, exposure to the ordinary climatic conditions, in which, with other elements, direct sunlight has been more or less of in important factor.

In the natural course of events, when tuberculous material is expectorated hy a consumptive, all of the above conditions operate in a greater or less legree to bring about the attenuation, and, finally, if the process is not interfered with, the complete destruction of the infecting power of such material.

In attempting to test any one of the above conditions separately, in as far as this is possible, one is met at the ontset by the difficulty that in nilure these conditions co-operate for the most part simnltaneously; and thus the singling out of any one particular process, and subjecting it to experiment, might be met with the criticism that such conditions would not occur naturally, and that therefore such conclusions would not be applicable. Nevertheless, since the experiments of Downes and Blunt with mixed cuitures, and Arluing with pure cultures, clirect sumlight has been regarded as the most powerful natural agent in destroying the virulence of pathogenic Lacteria; and 
we feel that we are justified in selecting this one natural agent as a criterion to determine, in a large measure at least, the time nature would take to render such material imnocuous.

The first recorded experiments in this direction are those by Feltz. ${ }^{1}$ He made a mixture of soil and tuberculous sputum, rich in tubercle bacilli. This was exposed to the direct rays of the sun, commencing on 13th September 1887. After 137 days' exposure such material caused tuberculosis when inoculated into guinea-pigs, but beyond this length of time it had lost its virulence. The same author makes the extroordinary statement that a portion of the same mixture of soil and tuberculous sputum, when exposed to the changing climatic and atmospheric conditions as they occur naturally, retained its virulence for but a little over two months. The mixture was subjected to the inclemencies of the weather by exposure in a box, the lid of which was pierced with numerous holes.

In the same year that this publication appeared, it was the privilege of one of us (Mitchell) to hear Rohert Koch make the statement before the Tenth International Medical Congress at Berlin, that the tubercle bacillus was killed by direct sunlight in from a few minutes to several hours, according to the thickness of the layer in which it was. exposed, and that diffused daylight accomplished the same in five days. This statement occurs in the Transactions of the Congress, ${ }^{2}$ but we have been unable to find any record of the experiments themselves, and we infer that he used pure cultures of the bacillus. Whatever of this may be true, with reference to the tubercle bacillus in pure culture, this statement surely does not apply to the tubercle bacillus as it is contained in expectorated tuberculous matter, the condition chiefly with which the sanitarian has to deal. Wre felt that such a statement, from so eminent an authority as Professor Koch, has given many sanitarians a false sense of security, and it was mainly to determine for ourselves if such was the case that these experiments were instituted.

The next recorded experiments are those by Mignaceo. ${ }^{3}$ This author adopted the methol of spreading sputum, rich in tubercle bacilli, on linen and woollen cloths, stretching them on a frame, and exposing them to the direct rays of the sun. The experiments were commenced :ist July 1894, and ended 22 nd September of the same year. After clifferent lengths of exposure, either small pieces of cloth were cut from the frames, moistened, and then inoculated subcutaneously into guinea-pigs and rabbits, or the cloth was soaked in sterile water, and squeezed out as thoronghly as possible, and this

\footnotetext{
1 "Essai experimental et clinique sur le rôle des ponssieres Bacillares dans la contagrion de la tubreulose et sur la durée de la virulence de ces Poussieres," Nancy, 1890.

2 Verinemall. 1. X. internat. med. Cung., Berlin, 1890, S. 42.

3 "Azione della luce solare sulla virulenza del bacillo tubercolare," Anm. cl. Ist. d'iy. sper. d. Cuiv. di Rome, 1895, tomo v. fasc. ii. p. 216.
} 
liquid injected into the animal. Mignaceo's conclusions were as follows :-

"(a) Sunlight exercises a deleterious effect on the tubercle bacillus, just as it does on other bacteria.

"(b) Tubercle bacilli, as found in tuberculous sputum, and spread on linen or woollen cloths, are not able to withstand the influence of direct sunlight for more than twenty-four to thirty hours, provided it is not spread in too thick a layer.

" (c) The virulence of the tubercle bacillus diminishes gradually after from ten to fifteen hours' insolation, and eventually, in the above given time, entirely loses its virulence."

Since our work in this direction has been completed, Gardiner, in an article on "Tubercular Infection," 1 mentions having exposed tuberculous sputum to the direct rays of the sun for one and threequarter hours, two hours and five minutes, and twenty-four hours. The material first exposed caused general tuberculosis; the second general tuberculosis in one, and local tuberculosis in two animals; the third caused local tuberculosis.

In short, then, our knowledge of the influence of insolation on the tubercle bacillus or on tuberculous sputum is as follows: According to Feltz such material is still virulent at 137 days : according to Koch the bacillus is killed in from a few minutes to several hours; Mignaceo, from twenty-four to thirty hours; Gardiner, experiments not comprehensive enough to draw conclusions.

Our experiments were commenced in the latter part of September 1897. The plan was to deposit on a sandy soil as much tuberculous sputum as a patient in the second or third stage of phthisis usually expectorites when walking about. This was then exposed to the direct rays of the sun for varying lengths of time, and its virulence tested by the inoculation of guinea-pigs.

After several attempts we were fortunate in finding a sputum which was expectorated in large quantities, and which the microscopical examination showed to be remarkably free from all bacteria other than the tubercle bacillus. This was of especial importance, as it was intencled to make the injections intraperitoneally, and acute septic infection had especially to be guarded against. That we were successful in this regard is shown by the results obtained, as only one of the animals injected succumbel to septicania. This sputum was obtained from a patient in the practice of Dr.S.A. Fisk. The patient was in the third stage of phthisis, and has since died. Our technique was as follows: The morning sputum was allowel to remain for two hours in a sterilised filter paper and fumnel, so as to drain off as much of the saliva as possible. Then this mixture was stirred with a sterile glass rod, so as to make it as homorgeneous as possible, and thus lessen the chance of exposing or injecting bronchial secretion not containing

${ }^{1}$ Am. Jouria. Med. Se., Plila., February 1898. 
tubercle bacilli. Four grms. of this sputum were then weighed, placed on a sandy soil, and exposed to the sun's rays. The soil was placed in the lower half of a Petri dish, and sterilised for two hours at $150^{\circ} \mathrm{C}$. When the allotted hours of exposure had terminated, the sputum, which after the first several hours of exposure had formed a firm crust, and could easily be lifted on masse, was taken from the soil with a sterile spatula, aml dissolved in 6.5 c.c. of sterilised distilled water. One c.c. of this mixture was injected intraperitoneally. Beginning on the 28 th September, the sputurn was exposed daily from 10 A.s. to 4 P.s. to the direct rays of the sun. When the day was hazy, or the sum under a cloud, the boards on which the Petri dishes and their sputum were exposed were placed in a dark chamber. The same chamber, which was a large unused incubator, served also as a resting place for the sputa at all times when they were not exposed to the sum. The days on which the exposures were made are given in the table below. The dishes were exposed to the sun on a broad ledging, running along the outside of the bacteriologrical laboratory of the Denver Health I)epartment.

In order to test the virulence of the sputum, two guinea-pigs were inoculated as controls. One died after twenty days and the other after six weeks, both presenting the typical lesions found in tuberculous guinea-pigs. At the conclusion of the experiments, two pigs, which were bought at the same time and hept under the same conditions as the inoculated guinea-pigs, were killed and found healthy. With the sputum, which was exposed to the different insolations, two pigs each were inoculated. The hours of exposure were as follows:$1,2,4,7,10,15,20,25,30,35,45$, and 55 hours, and the time taken to obtain the fifty-five hours of sunshine was, from 28 th September to 22 nd October 1897 . At the autopsies, which were conducted with great care in every case where an animal had been inoculated, sections were made of one or more of the organs and examined for the tubercle bacillus, and, provided this test failed, sections were stained and studied histologically.

The autopsies revealed that sputum, which had been exposed up to thirty-five hours, was still virulent. However, in only one of the two animals injected with the sputum, insolated for thirty-five hours, was tuberculosis produced. The other animal was tuberculous, it is true, but from what follows it will be seen that this animal suffered from inhalation tubereulosis.

An abstract from the autopsy of the first pig inoculated with the thirty-five hour material shows the following:-Spleen and liver contain few tubercles; tubercle bacilli demonstrated in sections of the spleen; histologically, also, typical tubercles were present with the exception that there were no giant cells. Diagnosis, general tuberculosis. This guinea-pig gave birth to two young on 9 th December, about seven weeks after she was inoculated, and at the time she was killed she 
was fairly well nourished, and had suckled her young with apparent comfort. The tuberculous virus aiter this length of exposure, although it could still produce tuberculosis, had greatly lost its virulence. The two pigs born were killed about a month later, and were found healthy and fairly well nourished.

An abstract from the autopsy of the second animal, inoculated with the material exposed for thirty-five hours, shows the following :-Peritoneum clear; liver and spleen normal; lungs contain a few tubercles; bronchial glands enormously enlarged. Sections of spleen show no tubercle bacilli; histologically, normal tissue found. Section of bronchial glands contain mbercle bacilli. Diagnosis, inbalation tuberculosis.

At first sight it may seem a difficult or even a dangerous proceeding to classify as infected with tuberculosis from inhalation an animal inoculated with material which, in fact, was also under trial as to its own power to cause a tubercular infection. Such is not the case, however, as the artificially coniracted (when such is not caused by inhalation), and the naturally contracted, tubereulosis of guinen-pigs and rabbits are as easily distinguished, one from another, as if they were separate diseases, provided one does not allow animals to live too long a time after work with tuberculous material has commenced. If such animials are guinea-pigs, we believe that all animals that have not died within eight weeks should be killed, as up to this time, if the animals are tuberculous, it can be readily told whether the disease has been spontaneonsiy acquirel or is the result of the inoculation.

Koch, in speaking of this subject in his epoch-making work on "The Etiology of Tuberculosis," 1 says: "Among many hundreds of guineapigs and rabbits which were bought for experinental purposes, were experimented upon and finally cane to autopsy, not a single animal was encounterel which was tuberculous. Only, after experiments with tuberculous material had commenced, and there were a large number of tuberculous animals in separatc cares, but in the same room with other animals, it was observed that isolated cases of tuberculosis occurred among the lattes animals. In such animals the tubercular symptoms were never noticeable until the animal had been at least from three to four months in a room with tuberculons animals. It was also characteristic that when the number of artificially infected animals diminished, the number of cases of spontaneous tuberculosis diminished likewise, and wice vess . . . The changes which are found in animals dead of spontaneous tuberculosis thfer in a very cbarncteristic mamer from those origrinating from an artificial infection, so that the different way and manuer of the infection may be recognised with all positiveness. In animals afticted with spontaneous tuberculosis there were regularly found in the lungs one or several

"Spontane Tuberkulüse der Meerschweinchen n. Kaninchen," Mitth. $a . a$. $k$. Gsnilhtsumte, 1 set. 
large tuberculous foci in advanced caseation, and at the same time considerably enlarged and caseous bronchial glands. Sieveral times the foci in the lungs were missing, and only the enlarged glands with caseous glands contents were present. The tuberculons changes of the other organs were proportionately less advanced." In animals inoculated with tuberculous material, otherwise than by inhalation, " the bronchial glands were so small that they could scarcely be found. Also, in these cases, the liver and the spleen suffered the greatest tubereulous changes, while the tubercles in the lungs were relatively small."

The changes thus described by Koch are what we found in the two animals, which we claim died of inhalation tuberculosis. The abdominal organs were healthy, and only the lungs and bronchial glands were infected. If the material, which in all of our animals was injected intraperitoneally, had been virulent, it would not have been probable or even possible that it would have passed by the peritoneum, the spleen, and the liver-three choice places for development-to infect only the lungs. In both of the cases with the enlarged tuberculous glands, the peritoneum, spleen, and liver were free from disease.

The aninals which were inoculated with the sputum exposed from one to twenty-five hours were all tuberculous, with the exception of one of the two injected with sputum which had been exposed seven hours, and this pig died nine days after the inoculation of an acute septiciemic infection. In the other animal, the seven-hour exposed sputum caused general tuberculosis.

In the sections of the organs taken from the animals, which were inoculated with sputum exposed from one up to seven hours, the tubercle bacilli were present in such great numbers that it seemed almost incredible that animals which are so susceptible as guinea-pigs, were able to live as long as they did. From the ten-hour on up to the thirty-five hour exposure, the tubercle bacilli conld only be demonstrated after considerable search, and in some cases, where characteristic tubercular lesions were present, histologically, no bacilli could be detected.

The sputum exposed above thirty-five hours, i.e. at forty-five and fifty-five hours, failed to canse tuberculosis. In one of the "fortytive-hour" injected pigs we found the liver, spleen, and abdominal contents free from tubercular disease, both macroscopically and microscopically, whereas the lungs contained a few large tubercles, and the bronchial glands were enormously enlarged and tuberculous. According to Koch, we must classify this as inhalation tuberculosis also. It is worthy of note that both this animal and the other which contracted tuberculosis were in cages standing almost directly on the floor, whereas the other cages were elevated somewhat.

Ore of the "fifty-five-hour" exposure guinea-pigs succumbed from 
pneumonia on 5th December, and at the autopsy no signs of tuberculosis conld be detected, and since death occurred nearly seven weeks after the inoculation there was anple time for tubercular development, provided the sputum inoculated had been virulent. When we examined sections of the pneumonic lung under the microscope, unstained and in salt solution, we thought we hikl to do with a genuine fibrinous pneumonia, in the alveoli appeared almost entirely occluded; however, when sections were stained and mounted, it was found that the occlusion was due to the enormously congested vessels and the swollen nucous membrane.

One or two of the animals of the earlier injections, which were very feeble and emaciated, and would unquestionably have died in a sbort time, if left to themselves, were purposely killed, in order, if possible, to obtain a pure cuiture of the tubercle bacillus. Out of about forty tubes inoculated with portions of disseeted-out tubercles, we succeeded in starting one pure culture.

A summary of these results sbows-

1. That the tubercle bacillus, as expectorated on a sandy soil, is still virulent after thirty-five hours' exposure to the direct rays of the sun in this altitude.

2. That such sputum has suffered but little apsreciahle diminutiou in virulence after twenty hours' exposure.

3. That after from twenty to thirty-five hours' exposure, the virulence is gradually diminished and finally lost if the exposure extends beyond the last-mentioned time.

The conclusion which we draw as to the infectionsness of sputum, as expectorated by consumptives in this altitucle while engaged in their daily avocations, is that such sputum has ample time to become desicated and blown in the atmosphere before being robbed of its power to cause the tuberculosis, if inhaled by susceptible individuals.

Now, since there unquestionably exists a great degree of immunity against tuberculosis in this region and at this altitude, its explanation must be sought on other grounds than that exposure to sunlight robs the expectorated matter of its virulence, before it is blown about and inhaled. It is then in orcler to turn our attention to the effects of the climatological phenomena as we find them here on the vital forces of the individual.

A study of all the various meteorological conditions as we find them at sea-level, and the deviations from these normals as we find them in high altitudes, would be far beyond the province of this paper, but a few of these changes which bear directly on this subject may be considered here. First, as to the absence of moisture in the atmosphere. In high altitudes both the absolute and the relative moisture is low, and this, together with the much lessened atmospheric pressure and almost constant winds of greater or less degree, greatly facilitates evaporation. Thus there are created conditions extremely favourable 
for the abstraction of moisture by the atmosphere, from whatever substances it comes in contact with. In the so-called dry region of New Mexico, Arizona, Colorado, and Wyoming, this desicating power of the atmosphere is extreme, much greater than at corresponding altitudes in other regions. The moist surfaces of the lungs, in common with other moist surfaces, must sulter considerably more loss from moisture in this altitude than at lower ones; and it is this constant battle for moisture compensation, especially as it occurs in the Inngs, that we believe to be one, and by no means the least, of the factors which either aicls in granting such a large measure of immunity against tuberculosis here, or in arresting or retarding such processes in their incipiency. We know that the tubercle bacillus grows but poorly or not at all on media deficient in moisture, and while it hardly seems possible that there could be moisture enough extracted to leave the alveolar linings in a state too dry to offer a suitable nidus for the invading bacillus, yet it is not improbable that this constant and rapid pulmonary evaporation creates conditions extremely unfavourable to its development.

This absence of moisture in the atmosphere acts beneficially on the animal organism as a whole, expecially in the summer mouths, thereby giving an increased bolily vitality, when in other regions in the same temperature the individual experiences a bodily enervation. For example, if we take the actual temperature, as measured by the ordinary thermometer, for two cities nearly on the same parallel of latitude as Denver and Washington, one in a dry mountainous region and the other at sea-level, we find that the temperature in the hot summer months, as given by the ordinary thermometer, differs but slightly; but the sensation of temperature, the heat that the individual feels, is not measured by the ordinary thermometer but by the wetbulb thermometer, and the reading of this thernometer in the two cities mentioned would differ considerably, as the following table will show.

Uuring the hot spell of August 1896, we find the following differences registered between the air temperature as shown by the ordinary themometer, and the sensible temperature as shown by the wet-bulb thermometer:--

\begin{tabular}{|c|c|c|c|c|}
\hline & \multicolumn{2}{|c|}{ Dexter. } & \multicolumn{2}{|c|}{ WhansGtos. } \\
\hline & Air Temperature. & Wet Bub Temperature. & Air Temprerature. & Wet Bulb Temperature. \\
\hline Aug. 1: & $90^{\circ} \mathrm{K}$ & $58^{\circ} \mathrm{r}$. & $88^{\circ} \mathrm{F}$ & $78^{\circ} \mathrm{F}$ \\
\hline$" 13$ & $85^{\circ}$, & $59^{\prime}$, & $70^{\circ}$, & $70^{\circ}$, \\
\hline " 14 & $90^{\circ}$ & $59^{\circ}$, & $78^{\circ}$, & $72^{\circ}$ \\
\hline " & $85^{\circ}$, & $59^{\circ}$, & $80^{\circ}$, & $72^{\prime}$, \\
\hline
\end{tabular}


Or, to take a single clay, we find that ou 12 th August while the people in Denver apparently were suffering from a temperature of $90^{\circ}$, iu reality the heat they felt was $32^{\circ}$ less. On the same date in Washington there was but $10^{\circ}$ difference between the two temperatures. This difference in temperatures the year around, but more marked in summer, exercises a decidedly tonic effect on the systen. Sunstrokes originating here are unknown.

The next meteorological phenomenon which apparently contributes so much, both directly and indirectly, to the placing of the human organism in a position to resist the invasion of tulvercle bacillus by way of the lungs, is the lessened atmospheric pressure. From a little less than $15 \mathrm{lb}$. at sea-level this pressme is diminished about one-half pound for each $1000 \mathrm{ft}$. ascension. At I)enver, with its altitude of $5290 \mathrm{ft}$, from a comparison of the barometric readings here with those at sea-level, the atmospheric pressure is found to be $1204 \mathrm{lb}$. per sq. in., a loss of nearly $3 \mathrm{lb}$.

We know that when the animal organism is subjected to increased atmospheric pressure, the blood is caused to recelle from the capillaries of the skin and mucous membrane, thus producing an anamia of these parts. The reverse of this is true when the organism is subjected to a diminished atmospheric pressure. In extremely high altitudes the diminished air pressure canses a great dilatation of the capiliary vessels of both skin and mucous membrane, causing a mechanical hyperimia. Indeed these vessels are often ruptured, and we may have hatmordhage from the mucous membrane of the nose, month, or even the lungs; the tympanum is bulged outward, the respiratory and cardiac movements are yuickened, and muscular motions are facilitated. In short, we have the conditions lescribed by adventurous mountain-climbers, and kllown as mal de montagne.

At Denver, with its reduction of nearly $3 \mathrm{ll}$. to the sq. in., we have all of the above symptoms produced, but on a scale of so much less intensity that they are scarcely noticeable; nevertheless, altbough this force works almost imperceptibly, it works none the less surely. This diminished pressure, while it operates on the skin ant mouns membrane as a whole, acts particularly on the lungs, causing a lilatation of its capillary vessels and a slowing of the hlind stream; the thorax is expanded, and there is an increased frequency of respiration as the amount of oxygen is diminished in the rarefied air, and there is the necessity for the greater consumption of the sime, so that the blood may receive its normal amount of oxygen. The heart's action is also increased so as tr aid in this compensation. These: changes all contribute directly to the specific nourishment and resisting power of the lungs. Nor is this all. The diminished pressure on the surface of the botly causes the body wimth to be easily and continuously lost and in large quantities. To compensate for this, other things being equal, the appetite is better, the metabolic changes 
more rapid and complete, and the need for nourishment greater. Moreover, as a result of the constant evaporation from the surface of the body, the specitic gravity of the blood is greater; also, we are told, that in a given quantity of blood, both the number of red blood cells and the percentage of hemoglobin is increased.' All of which changes are directly beneficial to the resisting power of the blood.

In reviewing this work, we find that there are two elements which militate against the spread of tuberculosis in high altitudes-(1) the powerful infuence of the sular rays, acting through a thin atmosphere, rapidly destroys the virulence of the exposed tuberculous matter; (2) the vital functions are so operated on by the various meteorological phenomena, that they are especially fortified against the invasion of the tubercle bacillus. We believe that our experiments clearly demonstrate that the immunity does not proceed from the first of these theories, and that we have every logical right to attribute it to the second proposition. When we consider that there are mechanical changes induced by this climate, which increase the exposure area of the blood in the lungs, and that the blood stream is slowed, so that, so to speak, it may the better give battle to the invading enemy; and that also, as a direct result of climatic conditions, this blood undergoes changes which make it stronger in the elements of resistance, the "alexines" of Buchner or the "protective proteids" of Hankin, the inference seems almost absolutely correct. These conclusions are further supported by the fact of the healing or retarding of cases of phthisis which come to this region in the early stages.

In conclusion, we think that these experiments are ample warrant for a greater degree of precaution in the disposal of tuberculous matter. We know of many physicians here who personally believed that the climatological conditions of themselves were amply sufficient to render the virus innocuous; and prior to these experiments we ourselves were of the opinion that a much shorter time was required than has provel to be the case. We trust that these observations may be the means of awakening renewed interest in prophylaxis.

It is with pleasure that we desire to acknowledge our thanks to Dr. S. A. Fisk for the interest and financial aid with which he has followed this work; to Health Commissioner W. I. Mum for having so kindly placed at our clisposal the facilities of the Laboratory of the Jenver Health Department; and to Mr. F. H. Brandenburg, local observer of the United States Weather Bureau, for valuable meteorological data.

'The data with reference to the effect of high altitude on the system are taken from "Witterung u. Klima," "Grundriss der Hygiene," Flügge. 
WILLIAM C. MITCHELL AND H. C. CROUCH.

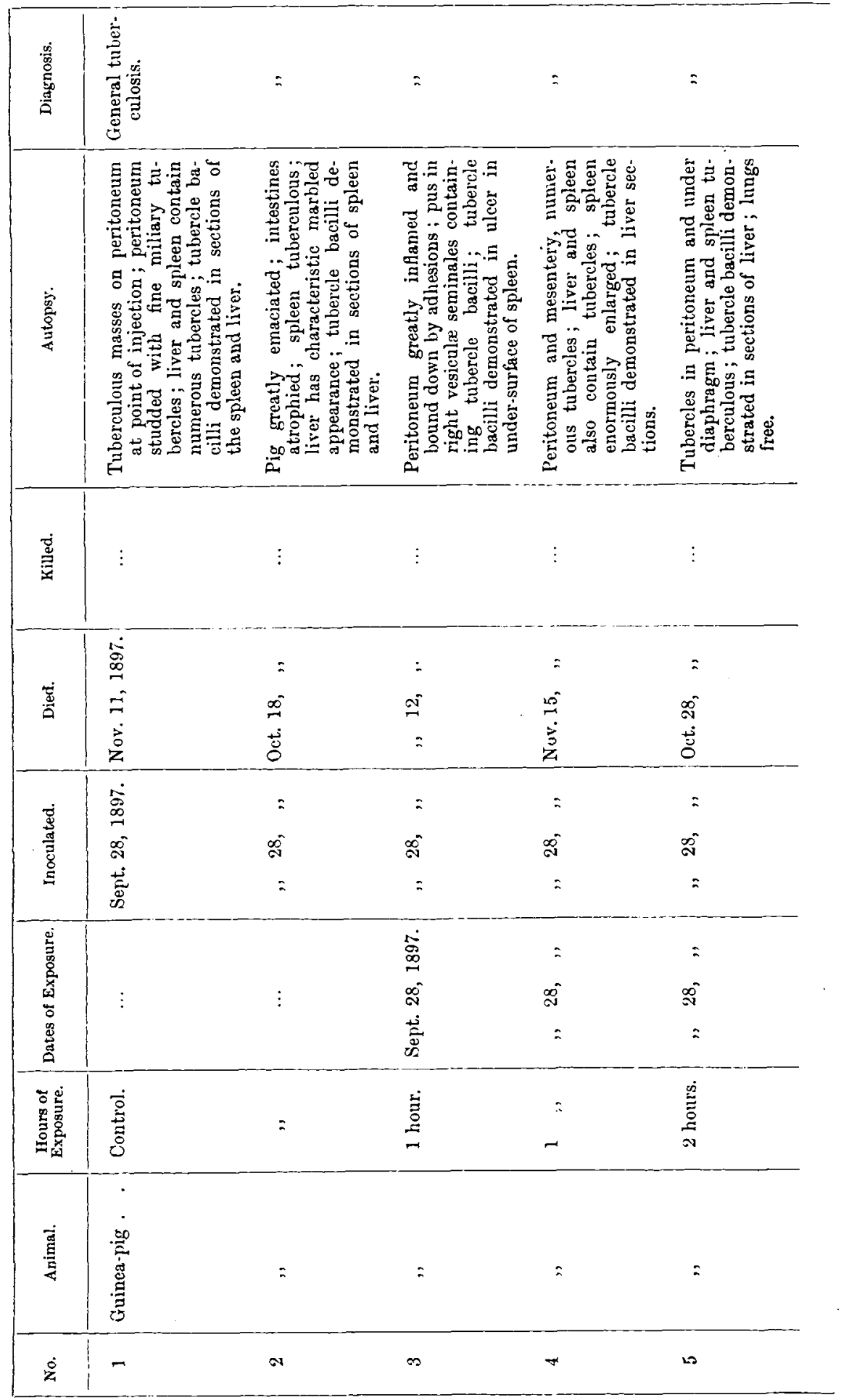




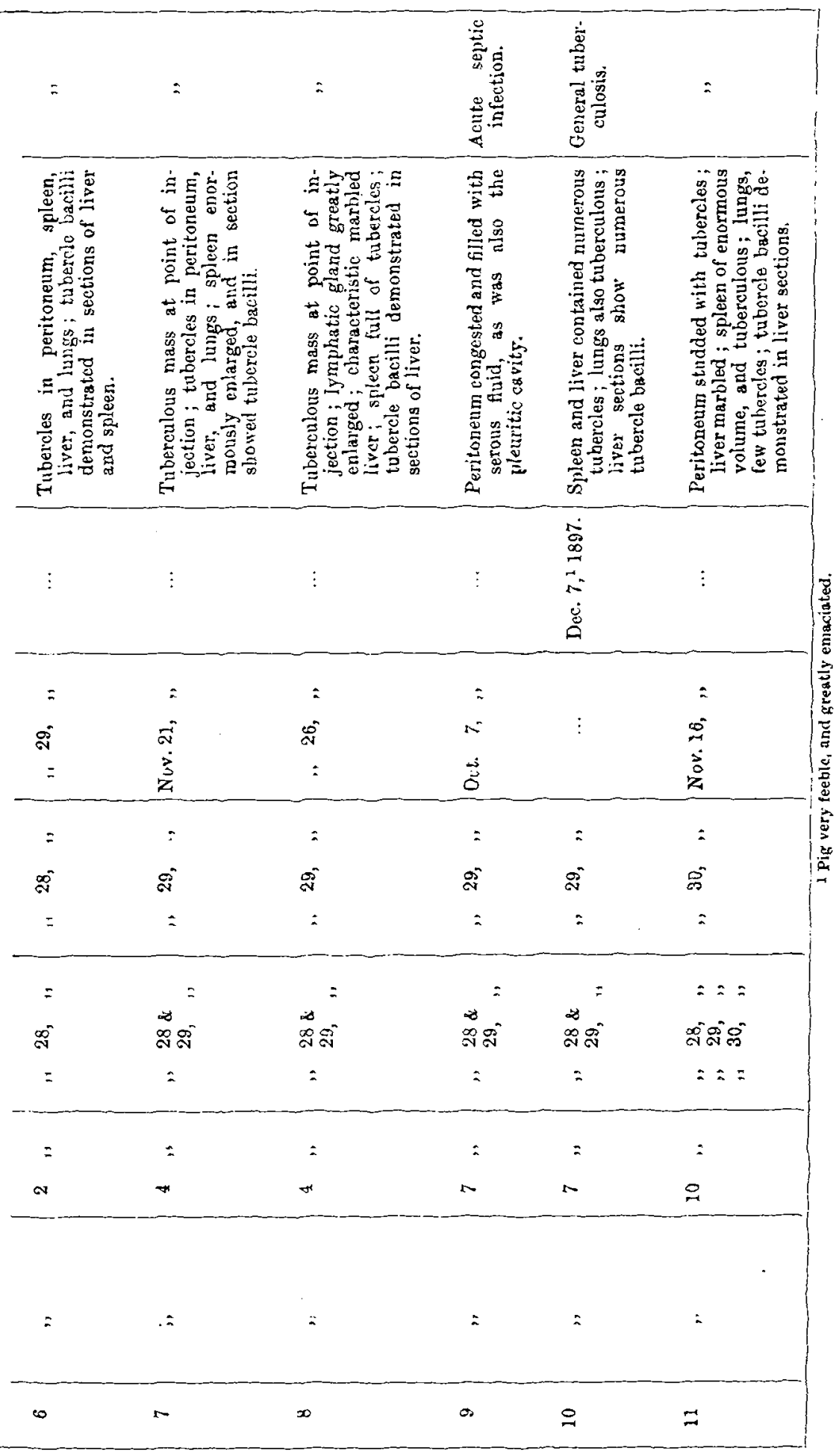




\begin{tabular}{|c|c|c|c|c|}
\hline 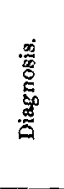 & 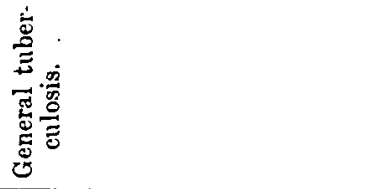 & $\therefore$ & $\therefore$ & $=$ \\
\hline 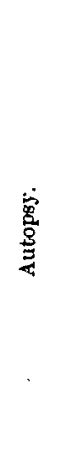 & 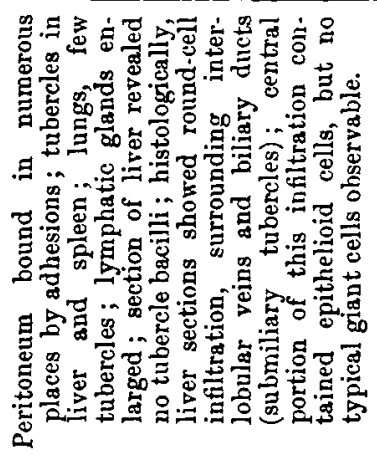 & 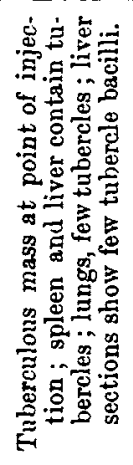 & 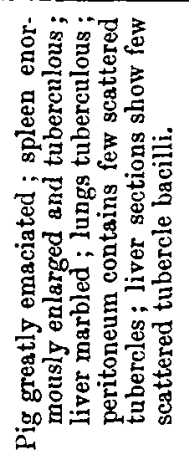 & 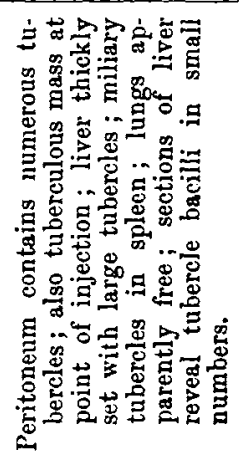 \\
\hline 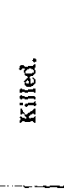 & 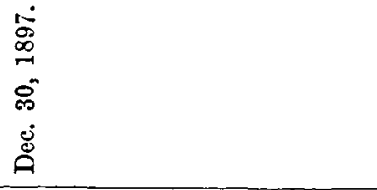 & $\begin{array}{l}= \\
D^{\infty} \\
=\end{array}$ & $\vdots$ & $\vdots$ \\
\hline 苞 & $\vdots$ & $\vdots$ & 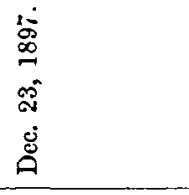 & 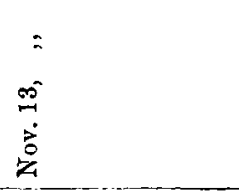 \\
\hline 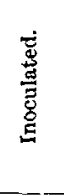 & 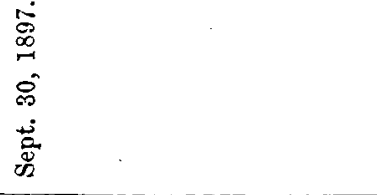 & $\begin{array}{l}\dot{ } \\
\text { iे } \\
\dot{0} \\
\dot{0}\end{array}$ & $\begin{array}{l}= \\
a \\
a\end{array}$ & $\begin{array}{l}= \\
\therefore \\
=\end{array}$ \\
\hline 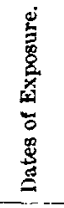 & 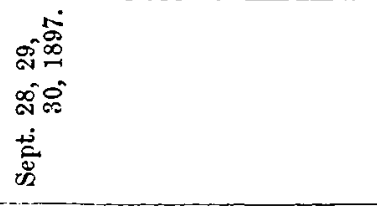 & 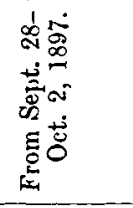 & : & 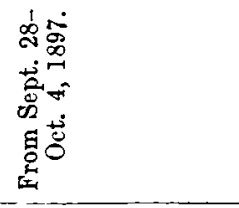 \\
\hline 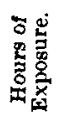 & 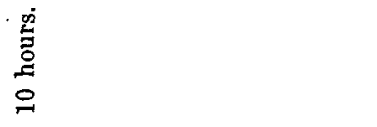 & $\begin{array}{l}= \\
\therefore\end{array}$ & $\begin{array}{l}= \\
\stackrel{2}{2}\end{array}$ & $\begin{array}{l}= \\
\text { \& }\end{array}$ \\
\hline 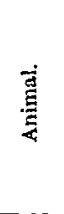 & 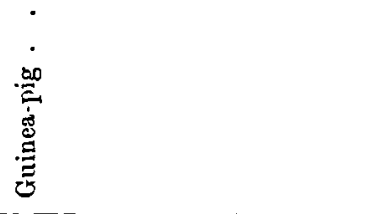 & $=$ & $\therefore$ & $=$ \\
\hline$\dot{\vec{z}}$ & $\cong$ & $m$ & 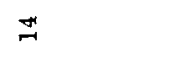 & $\because$ \\
\hline
\end{tabular}



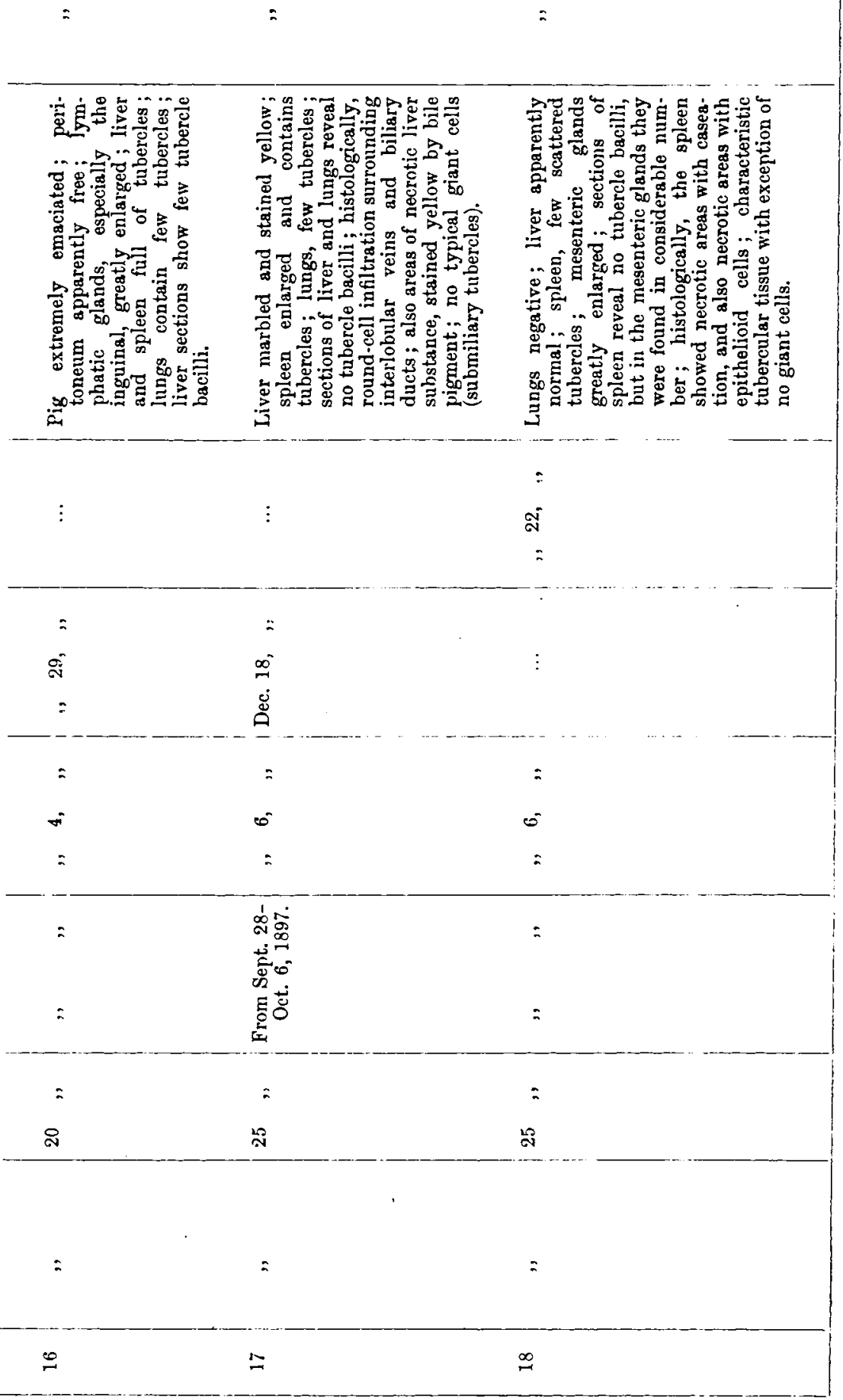


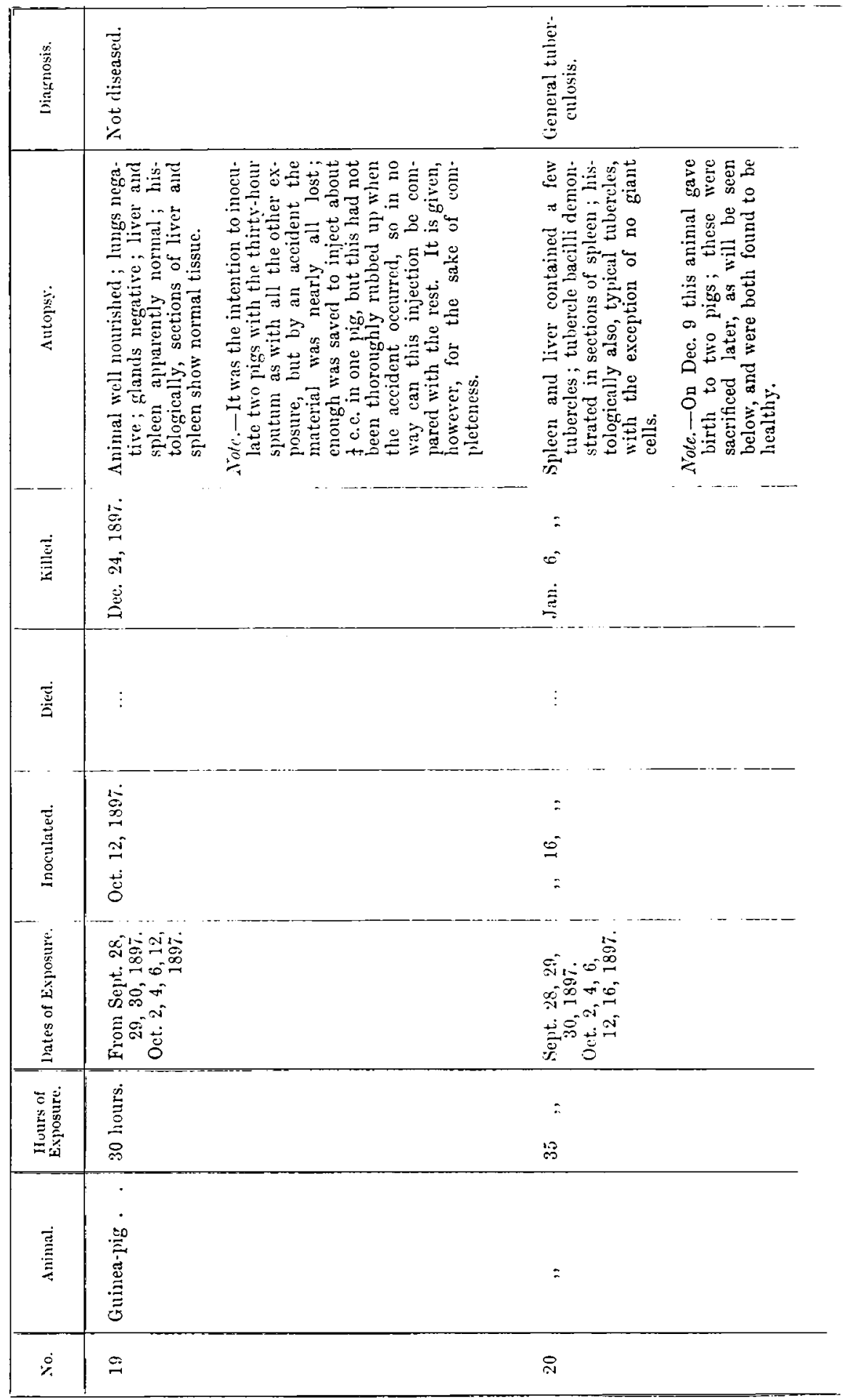




\begin{tabular}{|c|c|c|c|}
\hline 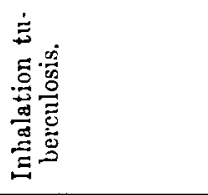 & $=$ & 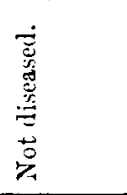 & 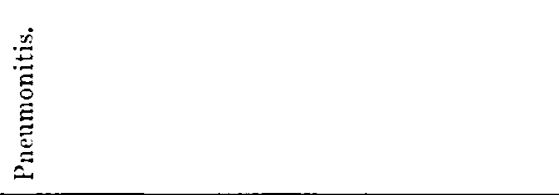 \\
\hline 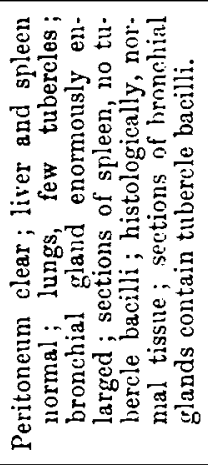 & 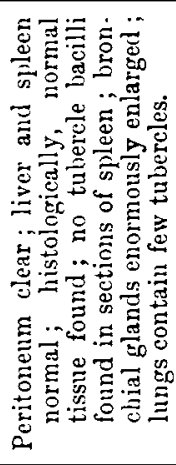 & 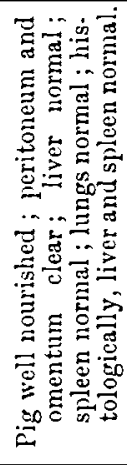 & 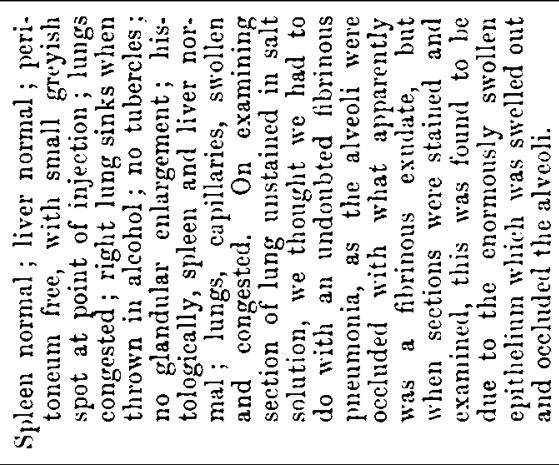 \\
\hline 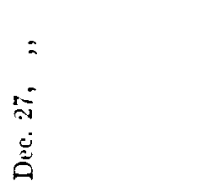 & 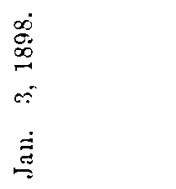 & 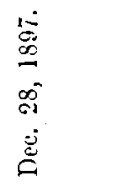 & $\vdots$ \\
\hline$\vdots$ & $\vdots$ & $\vdots$ & 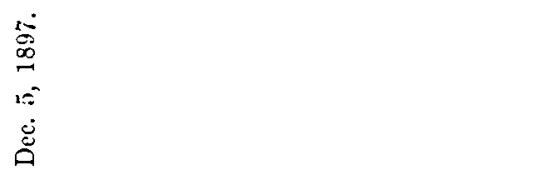 \\
\hline$=$ & $=$ & ; & $=$ \\
\hline$\stackrel{\circ}{\circ}$ & $\stackrel{8}{\circ}$ & $\stackrel{8}{S}$ & तิ \\
\hline$=$ & $=$ & $=$ & $=$ \\
\hline 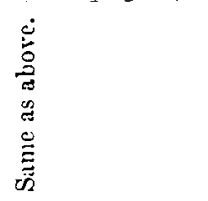 & 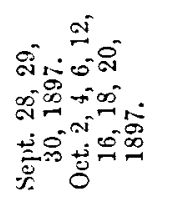 & 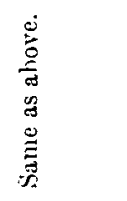 & 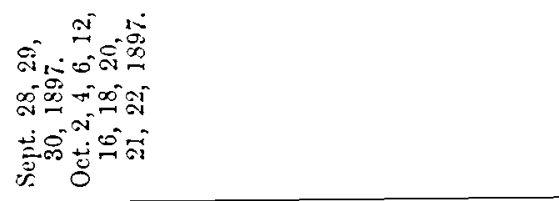 \\
\hline$=$ & $=$ & $=$ & $=$ \\
\hline$\stackrel{\circ}{\circ}$ & 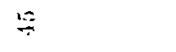 & 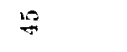 & : \\
\hline$=$ & $=$ & $\therefore$ & $=$ \\
\hline$\vec{\sigma}$ & 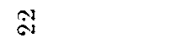 & $\hat{\mathrm{s}} \hat{i}$ & $\vec{N}$ \\
\hline
\end{tabular}




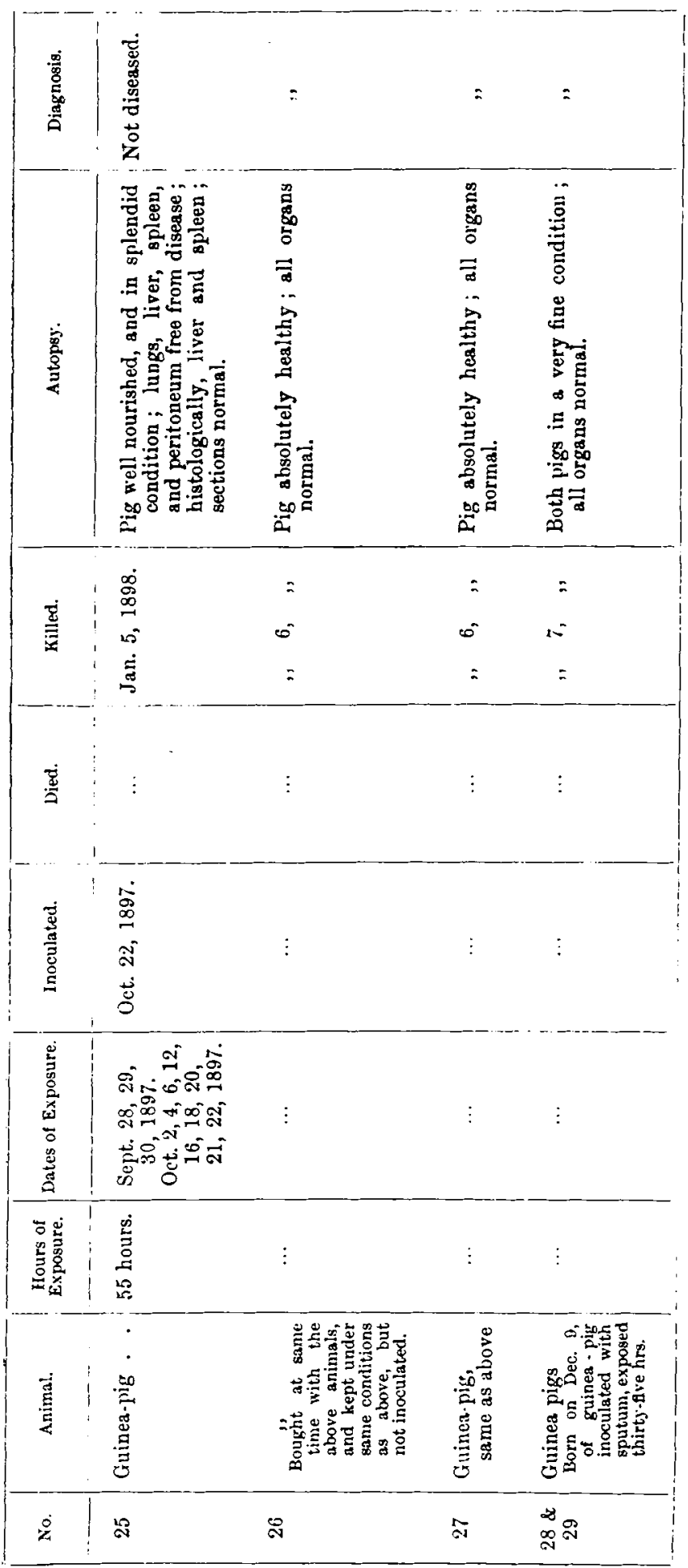




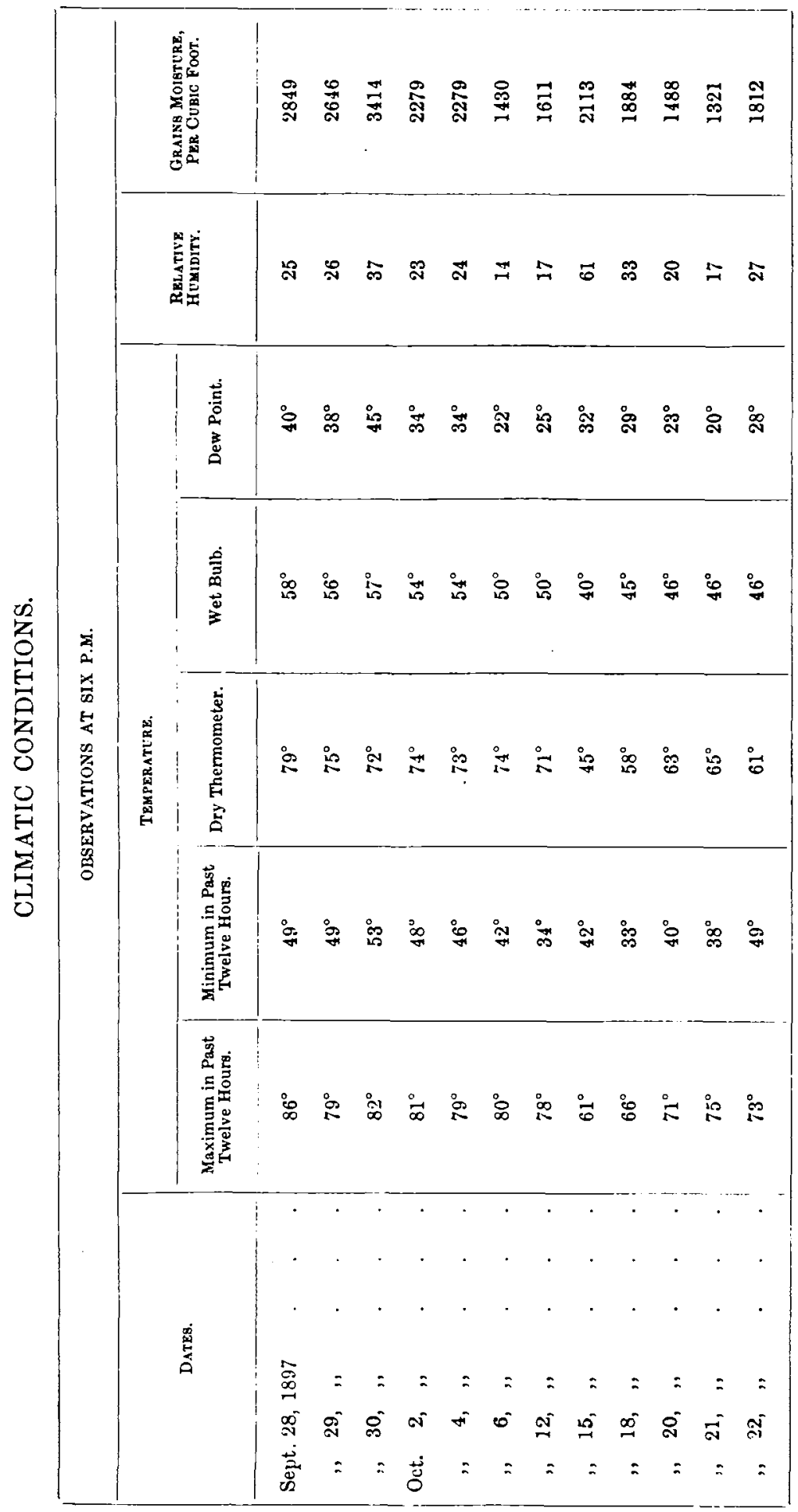

